\title{
Pendekatan Pendidikan Orang Rimbo Dan Masyarakat Sekitar Guna Mendukung Pariwisata Budaya Adat
}

\author{
Sri Walyoto \\ Institut Agama Islam Negeri Surakarta. \\ walyoto_colomadu@yaboo.co.id
}

\begin{abstract}
This study aims to determine the response of Rimbo people and the surrounding community about the establishment of Bukit Duabelas National Park. The study also estimates the value of tourism and culture among domestic tourists to the object using the Travel Cost Method (TCM). The results obtained by consumer surplus (CS) as much as US \$2.45 per visitor per visit. The result of CS value of each visitor shows the tourism services in the region does not provide high benefits to tourists. Bukit Duabelas National Park can be a domestic and international eco-cultural tourism destination and welfare improvement. It takes education awareness of tourism and traditional culture of Rimbo people and the surrounding community to achieve it.
\end{abstract}

Keywords: Indigenous Cultural-Tourism-Tourism, TCM, Bukit Duabelas National Park Development.

\begin{abstract}
Abstrak
Penelitian ini bertujuan untuk mengetabui tanggapan orang Rimbo dan masyarakat sekitartentang berdirinya Taman Nasional Bukit Duabelas. Penelitian juga mengestimasi nilai pariwisata dan budaya di kalangan wisatawan domestik ke obyek tersebut dengan menggunakan Metode Biaya Perjalanan (TCM). Hasil penelitian diperoleh surplus konsumen (CS) sebanyak US\$2.45 per pengunjung per kunjungan. Hasil nilai CS setiap pengunjung ini menunjukkan jasa wisata di kawasan tidak memberikan manfaat yang tinggi ke wisatawan. Taman Nasional Bukit Duabelas dapat menjadi tujuan pariwisata eko-budaya dalam negeri maupun internasional dan peningkatan kesejabteraan. Diperlukan pendidikan kesadaran pariwisata dan budaya adat orang Rimbo dan masyarakat sekitar untuk mencapainya.
\end{abstract}

Kata Kunci: Pendidikan pariwisata-budaya adat, TCM, Pembangunan Taman Nasional Bukit Duabelas.

Permalink/DOI:http://dx.doi.org/10.18326/infsl3.v11i1.207-228 


\section{Pendahuluan}

Pendidikan merupakan suatu pendekatan yang bijak untuk merubah tradisi/adat (urf) yang cacat/rusak (urf fasid) kearah yang benar (shabih). Para ulama menegaskan urf dapat dijadikan sumber hukum dengan syarat tidak ada yang nash dalam masalah itu. Seperti urf orang Rimbo dan masyarakat sekitar tetang penerimaannya kehadiran Taman Nasional dalam kehidupan yang telah dijalani. Dengan pendekatan pendidikan Taman Nasinal yang bertrujuan mensejahterakan masyarakat akan mendapat dukungan orang Rimbo dan masyarakat sekitar. Pengelola Taman harus percaya dan yakin dengan usaha yang sungguh-sungguh pasti Allah akan memberi kemudahan.

Allah telah berfirman dalam AL-Qur'an surat Al-Baqarah ayat 185;

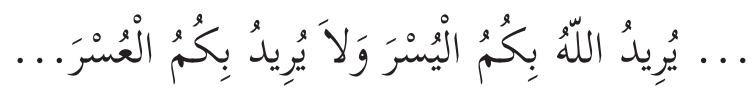

"Allah menghendaki kemudahan bagimu, dan tidak menghendaki kesukaran bagimu”... ."(QS.Al-Baqarah:185)

Dalam ayat ini Allah memerintahkan kewajiban puasa pada bulan Ramadhan, orang sakit bepergian membolehkan tidak berpuasa tetapi menggantinya dihari lain sebanyak hari yang tidak berpuasa. Ini karena Allah menghendaki kemudahan dan tidak menghendaki kesukaran bagi umat manusia. Dari ayat tersebut manusia perlu berfikir dalam kepentingan lain yang terkait dengan firman ini. Manusia wajib berusaha dan beriktiar dengan berserah diri pada Allah. Kemudahaan keberhasilan itu hak Allah. Sebagaimana pemerintah/pengelola Taman Nasional Bukit Duabelas dalam pembangunan Taman Nasional, wajib berupaya agar tujuan mulia untuk kesejahteraan masyarakat dapat tercapai. Upaya pemerintah (pengelola) dengan pendekatan pendidikan untuk memberikan pemahaman, kesadaran orang Rimbo dan masyarakat sekitar dapat menerima dan mendukung pengelolaan taman.

Pendidikan pariwisata dan budaya adat perlu ditanamkan kepada generasi muda sebagai penerus bangsa. Dengan pendekatan pendidikan diharapkan ditinggikan martabatnya dan ditambah luas pengetahuannya sebagaimana firman Allah dalam surat Al-Mujadalah ayat 11: 


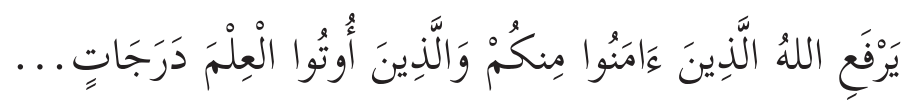

Artinya :"Allah akan meninggikan orang-orang yang beriman di antaramu dan orang-orang yang diberi ilmu pengetahuan."(QS.Al-Mujadalab:11)

Wisata alam seperti hutan lindung, tamannasional, air terjun, sungai, guwa memberikan tiga fungsi penting untuk kesejahteraan manusia seperti: fungsi pelestarian alam, fungsi pendidikan, serta fungsi rekreasi khususnya masyarakat kota yang ingin bersantai. Taman Nasional Bukit Duabelas merupakan perluasan dari Cagar Biosfier Bukit Duabelas. Pendirian Taman Nasional Bukit Duabelas berdasarkan surat keputusan Menteri Kehutanan Nomor 258/KptsII/2000, tanggal 23 Agustus tahun 2000 dengan luas 60.500 hektar (BKSDA 2004), Taman Nasional ini menjadi tujuan wisata alam dan budaya adat Suku Asli di Propinsi Jambi Indonesia.

Tujuan Taman Nasional Bukit Duabelas dikonservasi sebagai kawasan pengembaraan dan pelestarian budaya adat suku asli (Orang Rimbo) serta upaya pendidikan masyarakat setempat. Kebijakan pengembangan hutan Cagar Biosfier menjadi Taman Nasional Bukit Duabelas berdasarkan kepada empat isu iaitu; (1) perlindungan dan konservasi kawasan karena adanya konflik perebutan sumber daya alam, (2) penyelenggaraan usaha pelayanan wisata oleh masyarakat, (3) pemberdayaan Orang Rimbo yang masih terjadi beda pendapat dari banyak pihak, (4) pengelolaan multi pihak yang saling curiga menjadikan sumber konflik dan mempengaruhi kinerja dalam menjalankan misi luhurnya.

Pembangunan perkebunan kelapa sawit di hutan penyangga Taman Nasional Buklit Duabelas telah menimbulkan tekanan serta ancaman keberadaan Taman (KKI Warsi 2004). Permasalahan ini berujung pada timbulnya persoalan pendidikan, ekonomin dan budaya orang Rimbo dan masyarakat sekitar. Keberlanjutan Taman lebih nyata, sejalan fungsinya sebagai pendidikan dan pemberdayaan budaya suku asli (Orang Rimbo). Dipandang dari segi pendapatan belum nampak sumbangannya dan masih memerlukan perbaikan manajemen dan peningkatan melalui perbaikan pendidikan. Sehingga dari segi perspektif keuangan saat ini dapat dikatakan 
tidak layak. Pendekatan pendidikan diharapkan dapat meningkatkan pengetahuan orang asli dan masyarakat sekitar.

Dengan pendekatan pendidikan orang asli dan masyarakat sekitar dapat dilibatkan dan mendukung pembangunan taman. Tujuan pembangunan untuk peningkatan kesejahteraan masyarakat. Hutan sebagai sumber alam menyediakan berbagai aliran manfaat ekonomi seperti jasa pariwisata, aktivitas penelitian, serta berbagai fungsi ekologi yang tidak dapat ditangkap oleh mekanisme pasar biasa. Kesemua manfaat tersebut termasuk jasa bukan pasar (non-marketed benefits) karena tidak mempunyai harga pasar untuk menggambarkan kepentingan ekonominya (Jamal et al. 2004). Maka penilaian dilakukan dengan membandingkan antara pendapatan masuk serta biaya pengelolaan.

Tujuan penelitian ini untuk mengetahui (1) tanggapan orang Rimbo dan masyarakat sekitar pedekatan pendidikan tentang keberadaan Taman Nasional dan pengggunaan kawasan. (2) Mengestimasi nilai ekonomi pariwisata dan budaya adat. Secara spesifik, penelitian ini fokus pada estimasi nilai ekonomi manfaat yang diperoleh oleh wisatawan domestik ke Taman Nasional. Seperti telah dibahas dimuka, bahwa nilai ekonomi manfaat pariwisata adalah komponen manfaat pasar dan bukan pasar. Penelitian ini hanya mengestimasi nilai guna langsung yang memiliki harga pasar. Dalam mengestimasi manfaat pariwisata, penelitian ini hanya menunjukkan nilai batas bawah manfaat dari aliran manfaat yang disediakan pariwisata ke Taman Nasional Bukit Duabelas.

Hasil penelitian diharapkan dapat membantu pemerintah dan pengelola Taman dalam mengambil kebijakan pengelolaan.

\section{Nilai Ekonomi Pariwisata Budaya dan Pembangunan}

Peran budaya dalam pembangunan ekonomi bangsa dapat dipandang dari dua sisi. Pertama, untuk mempromosikan kemajuan ekonomi. Kedua, sebagai ciri peradaban yang memberikan arti kewujudan masyarakat suatu negara. Budaya dan pembangunan ekonomi juga berhubungan dengan pembangunan sumberdaya manusia. Pembangunan juga menempatkan budaya sebagai bagian dalam kelompok masyarakat tersebut. 
Konsep budaya dan pembangunan perlu diperhitungkan secara bersama-sama keduanya merupakan bagian dari budaya masyarakat. Pemahaman budaya yang lebih luas yaitu sebagai hasil dari suatu proses. Marshal dan Sahlin berpandangan bahwa hubungan budaya dan ekonomi adalah inklusif. Budaya dapat diartikan sebagai perwujudan kelompok nilai dan pembangunan sebagai proses untuk membantu manusia dalam memilih sumber alam yang terbatas.

Throsby (1997) berpandangan bahwa pembangunan ekonomi bangsa dan budaya merupakan suatu dasar yang tidak terpisahkan. Mendasarkan dari UNESCO dalam World Commission on Culture and Development (WCCD) disebutkan, bahwa budaya diletakkan sebagai bagian penting dalam pembangunan berkelanjutan suatu negara. Kayam (1996) juga berpandangan bahwa budaya itu abtrak dan memiliki batasan. Budaya dapat sebagai variabel yang mempengaruhi perubahan fenomena. Buday juga merupakan suatu proses dialektik yang dinamis dalam sistem ekonomi.

\section{Modal Budaya}

Modal dalam ilmu ekonomi seperti modal sosial (Soo-Hoon Lee et al. 2005), modal kepandaian (Caroll \& Tansey, 2000), serta modal budaya (Trosby 1999). Modal sosial dan modal kepandaian merupakan modal non-fisik yang tidak tampak dan dimiliki oleh masyarakat. Modal budaya dipergunakan untuk menjelaskan hal yang berbeda dengan arti yang berbeda. Modal budaya dalam teori Weber adalah efisiensi yang diperoleh suatu masyarakat.

Pandangan Hit et al. (2001) sumber alam utama lebih mahal untuk ditiru dan tidak ada subtitusinya. Sumber harus bernilai dan tidak dapat digantikan untuk menjadikan kompetensi inti. Selanjutnya harus unik dan tidak tergantikan menjadi ciri budaya suatu bangsa. Contoh, budaya Orang Rimbo, budaya Toraja, budaya suku Asmat, budya suku Dayak, budaya suku Badui dan berbagai karya dari suku primitif di Indonesia yang tidak dapat diciptakan oleh bangsa lain di dunia ini. 
Bagaimanapun budaya berkontribusi memberikan kontribusi pencapaian tujuan pembangunan ekonomi berkelanjutan. Keunggulan kompetitif dapat dimiliki jika bangsa dan negara dapat membangun ekonomi secara berkelanjutan, dapat mengelola sumber, produktif dan efisien sehingga secara akumulasi menjadi modal budaya.

Indonesia dianugerahi Tuhan dengan berbagai keunikan budaya dan alam yang indah. Keunikan tersebut telah menjadi daya tarik dan membedakan dengan budaya bangsa di lain negara. Keunikan tersebut menjadi modal dasar, khususnya modal budaya. Singapura misalkan, ia tidak mempunyai kekayaan alam seperti Indonesia, tetapi dapat menciptakan keunikan seperti, pameran, atau hanya pertemuan telah banyak dilakukan oleh pengusaha internasional yang dapat menjadi daya tarik negara tersebut. Demikian juga China daratan dengan keunikan pariwisata tradisional dan Hongkong telah menjadi tujuan pariwisata modern.

\section{Budaya dan Aset Generasi}

Aset kepentingan generasi sebagai bagian keadilan dalam mendistribusikan kemakmuran, utility atau alokasi sumber antar generasi. Aset kepentingan generasi prinsipnya dapat diartikan sebagai pandangan jauh kedepan demi generasi bangsa. Jika merujuk pada konsep budaya, bahwa budaya bukan produk akhir tetapi hasil ciptaan masyarakat. Kreasi dan inovasi dapat menghadirkan pembaharuan sehingga dapat memberi corak dan memperkaya budaya yang sudah ada. Proses memperkaya dan memberi corak budaya yang ada dilakukan oleh masyarakat dalam suatu peradaban. Proses tersebut berlangsung dari generasi ke generasi. Selanjutnya menjadi modal yang bernilai tinggi pada generasi tersebut. Budaya ciptaan suatu generasi menjadi daya tarik dan dapat menyangga ekonomi bangsa.

\section{Budaya dan Ekonomi Berkelanjutan}

Sustainability development sebagai konsep pembangunan di kenal dari tahun 1970-an. Konsep pembangunan tersebut menekankan 
perlunya suatu bangsa mempertimbangkan atau berfikir terhadap generasi mendatang. Kekayaan budaya merupakan potensi pengembangan perekonomian (Dewi Nurfitriyana 2010). Konsep sustainability development berarti tidak hanya sebagai pembangunan ekonomi, namun juga sebagai alat untuk menuju kepuasan intelektual, emosional, dan moral. Oleh karena itu, keberbagaian budaya menjadi dasar pembangunan berkelanjutan.

Keberbagaian budaya juga menjadi salah satu dasar pembangunan sosial, ekonomi dan lingkungan. Maka, memposisikan budaya sebagai modal pembangunan menjadi suatu yang penting. Bangsa dan negara yang memiliki modal tersebut idealnya efisien dan unggul bersaing ekonominya (Landiyanto dan Wardaya 2009). Juga dapat memperkaya potesi daerah wisata budaya sebagaimana penelitian Priyanto dan Dyah Safitri (2016).

\section{Budaya Adat dan Pembangunan Berkelanjutan}

Agenda 21 dalam Bab 26 terdapat dukumen penting pengakuan dunia kepada masyarakat adat sebagai bahagian dari pembangunan berkelanjutan. Sebagai negara yang mendukung dan menandatangani Perserikatan Lingkungan Hidup Internasional, dalam melaksanakan pembangunan ekonomi harus sesuai dengan aspirasi bangsa. Ini termasuk aspirasi masyarakat adat yang juga merupakan bagian bangsa tersebut. Masyarakat adat hidup secara berterusan, memiliki pengetahuan obat-obatan, pertanian, pemeliharaan Derah Aliran Sungai (DAS), pemanenan sumber alam secara berkelanjutan adalah asset pembangunan berkelanjutan (Ravi Goval 2005).

Seperti yang disebutkan oleh Hood Salleh et al. (2004), penelitian World Wide Fund for Nature (WWF) 2000 tentang keanekaragaman hayati daerah dan tradisional masyarakat adat dunia serta pemeliharaan, telah mendokumentasikan kehancuran bahasa yang diucapkan oleh masyarakat adat di seluruh dunia. Kegagalan untuk mendokumentasikan pengetahuan masyarakat adat telah menyebabkan kehancuran bahasa secara signifiken, yang menyebabkan kehilangan pengetahuan lingkungan dari budaya tradisional. 
Masyarakat adat Indian Maya di Amerika Tengah yang hidup pada tahun 2000 SM adalah petani sukses yang telah membangun beratus-ratus kota besar dari batu, masing-masing dengan watak sendiri dan gaya artistis. Oleh karena itu, menselaraskan pembangunan dan keberlanjutan masyarakat adat perlu pendidikan yang dirancang pemerintah setiap negara agar peradaban budaya adat yang bernilai tinggi tidak hilang karena modernisasi pembangunan.

\section{Metode Penelitian}

Penelitian dilakukan dengan metode kualitatif dan kuantitatif. Metode valuasi yang digunakan untuk estimasi nilai manfaat pariwisata budaya adat adalah Travel Cost Method (TCM). Metode Biaya Perjalanan (MBP) atau Travel Cost Method (TCM) meliputi (biaya perjalanan individu, hipotetik, zonal dan teori random), penilaian kontingen, metode harga hidonik dan pemodelan pilihan.

Travel Cost Method (TCM), nilai kawasan pariwisata ditentukan oleh pengeluaran biaya perjalanan dan lain-lain pengeluaran yang terkait dengan kepentingan menikmati aktivitas wisata. Kurva permintaan pariwisata ditentukan menggunakan metode ekonometri dengan data pengunjung, biaya perjalanan serta variabel sosio-ekonomi yang relevan. Manfaat wisata diestimasi berdasarkan luas daerah dibawah kurve permintaan pariwisata. Sedangkan manfaat bersih (surplus konsumen) dihitung dari daerah dibawah kurve permintaan pariwisata dan diatas garis harga. Kurve permintaan pariwisata dapat ditentukan dengan garis lurus (linear) dan garis lengkung (semi-log). Dalam penelitian ini menggunakan pembentukan kurve permintaan pariwisata dengan garis lengkung.

\section{Surplus konsumen (consumen surplus)}

Konsep consumen surplus mengukur pengaruh kesejahteraan individu dari perubahan permintaan konsumen karena adanya perubahan harga. Definisi consumen surplus secara umum berdasar pada kesediaan membayar yang lebih dari harga pasar yang sebenarnya dari barang tersebut. Perbedaan harga pasar dengan harga yang sanggup dibayar merupakan ukuran consumen surplus. 
Consumen surplus diukur melalui pembentukan kurva permintaan Marshallian. Kawasan di bawah kurve permintaan dan di atas garis harga pasar merupakan consumen surplus. Konsep consumen surplus ini merujuk kepada surplus atau perbedaan antara harga maksimum yang sanggup dibayar oleh konsumen untuk mendapatkan barang atau jasa berbanding dengan harga pasar yang semestinya dibayar.

Asumsi penting dalam Metode Biaya Perjalanan adalah terdapat hubungan negatif antara biaya perjalanan dengan kekerapan kunjungan. Maksudnya, individu yang berkunjung dari tempat paling jauh memperoleh surplus konsumen atau manfaat bersih sebanyak nol.

\section{Estimasi Nilai Pariwisata Budaya adat}

Langkah I, Membentuk fungsi permintaan kunjungan wisata budaya adat Orang Rimbo

Pembentukan fungsi permintaan kunjungan wisata budaya adat Orang Rimbo ke Taman Nasional Bukit Duabelas diestimasi dengan regresi berganda. Variabel terikat kekerapan kunjungan ke kawasan wisata bersangkutan. Varibel bebasnya, biaya perjalan ke kawasan wisata bersangkutan, pendapatan, umur dan bendidikan. Model persamaan spesifikasi seperti dibawah.

$$
L n V=\alpha_{0}+\beta_{1} K p+\beta_{2} P d t+\beta_{3} U m+\beta_{4} P e n d i k+u_{i}
$$

\section{Langkah II}

\section{Menghitung Surplus Consumen (CS)}

Kurve permintaan model semi log, surplus consumen (CS) setiap pengunjung dihitung dengan rumus (Gum dan Martin 1975; Hanley 1989; Jamal et.al 2004) seperti berikut:

$$
\begin{aligned}
& C S=\frac{1}{-\beta} \\
& \mathrm{CS}=\text { Surplus Consumen }(\mathrm{CS}) \\
& \boldsymbol{\beta}=\text { koefisien biaya perjalanan }
\end{aligned}
$$


Teori Metode Biaya Perjalanan (MBP) atau TCM umumnya menggunakan asumsi: (1) terdapat keadaan weak complementarity dan (2) weak separability dalam fungsi utility. Asumsi weak complementarity maksudnya marginal utility dari pariwisata adalah nol apabila tidak ada biaya perjalanan. Apabila biaya pariwisata ke suatu kawasan wisata semakin mahal maka kedatangan pengunjung menjadi tidak ada atau nol. Asumsi weak separability bermaksud fungsi permintaan pariwisata hanya dipengaruhi oleh sebagian biaya pengunjung yang relevan dengan sumber pariwisata yang dimodel saja.

Metode Biaya Perjalanan atau TCM tidak dapat digunakan untuk mengestimasi nilai pariwisata non-use (Larson 1992), dan juga kurang fleksibel untuk mengestimasi marginal manfaat akibat perubahan salah satu atau beberapa atribut yang membentuk jasa pariwisata itu. Penelitian ini hanya mengestimasi nilai pariwisata budaya adat di Taman Nasional Bukit Duabelaa (receational on-site use value.

\section{Sampel dan metode pengumpulan data}

Sampel penelitian ini berjumlah 400 responden. Teknik random digunakan untuk mengumpulkan informasi yang berhubungan dengan penelitian ini. Pengumpulan data dilakukan dengan menggunakan kuisioner. Responden dipilih secara random untuk pengunjung dewasa dengan memperhatikan agar tidak terjadi ganda responden dalam satu keluarga. Sampel diambil di Kabupaten Tebo, Kabupaten Batanghari dan Kabupaten Sarolangun dengan menggunakan kuisioner.

\section{Hasil Pembahasan}

\section{Analisis model TCM}

Manfaat berwisata dari segi ekonomi dan dalam suatu kasus dapat dianggap sebagai nilai penggunaan langsung (Kumari 1994). Manfaat wisata yang mempunyai ciri berbentuk bukan pasar fungsi permintaannya tidak dapat diestimasi dengan model estimasi biasa. 
Model penilaiannya berdasarkan teori konsumen dan kriteria ekonomi kesejahteraan. Model yang biasa digunakan antaranya Travel Cost Method (TCM) (Cesario 1976). McConnell (1985) juga telah menggunakan model biaya perjalanan untuk mengestimasi permintaan terhadap kawasan pariwisata dengan menggunakan variasi biaya perjalanan setiap pengunjung ke kawasan pariwisata. Setiap individu mengeluarkan biaya perjalanan yang berbeda untuk sampai ke kawasan pariwisata tertentu.

Pengukuran surplus konsumen dalam penelitian ini mendasarkan pada teori pemikiran ekonomi neo-klasikal (neoclassical economic theory). Teori tersebut juga dikutip oleh Fauzi (2004) beliau menjelaskan bahwa pengukuran barang dan jasa hasil sumberdaya alam dapat ditunjukan dalam perubahan surplus konsumen.

Asumsi yang digunakan untuk membentuk fungsi permintaan pariwisata budaya adat Orang Rimbo dan keasrian alam adalah sebagai berikut:

i. Kawasan wisata merupakan tujuan utama bagi setiap kunjungan yang dilakukan oleh pengunjung.

ii. Setiap pengunjung menyadari sembarang perubahan biaya berkaitan dengan biaya perjalanan menuju ke kawasan.

iii. Tidak terjadi sembarang pengorbanan biaya untuk waktu yang digunakan dalam perjalanan ke kawasan.

iv. Tiada kawasan wisata budaya adat Orang Rimbo alternatif untuk pengunjung.

v. Jangka waktu yang diluangkan oleh setiap pengunjung, dilakukan dapat melakukan pengukuran kunjungan dalam satu skala.

Dari sampel yang ditetapkan, sebanyak 41 observasi disensor karena data rusak. Fungsi permintaan wisata budaya adat Orang Rimbo dan keasrian alam di kawasan diestimasi dengan spesifikasi model kuadrat terkecil (OLS) menggunakan data dari responden yang telah diwancarai. Biaya perjalanan dihitung dari perkalian jarak pergi dari daerah asal ke kawasan wisata dengan kendaraan umum berdasar SK Gubernur. 


\section{Langkab I}

\section{i.Hasil Regresi Fungsi Permintaan Wisata Budaya Adat}

Hasil regresi semi-log variabel terikat untuk membentuk fungsi permintaan kunjungan wisata budaya adat. Nilai $\mathrm{F}$ dari model yang dibentuk adalah tepat dan signifikan pada $\alpha=0,01$. Nilai $R^{2}$ merupakan indeks yang menerangkan variasi kunjungan yang dapat diterangkan oleh variabel bebas (indevendent). Secara umum nilai $\mathrm{R}^{2}$ dalam model yang dibentuk varibel terikat (kekerapan kunjungan) dapat diterangkan sebanyak 73,5\% variabel bebas (biaya perjalanan, pendapatan, umur, pendidikaan). Model ini juga tidak mengalami masalah kolinearitas berganda yang serius berdasarkan statistik 'Condition Index-CI'. Model yang diestimasi juga tidak mengalami masalah autokorelasi yang serius berdasarkan uji Durbin-Watson (D.W).

Model menunjukkan variabel $K P$ (biaya perjalanan pergi balik ke kawasan penelitian) mempunyai hubungan yang negatif dengan kekerapan kunjungan dan signifiken pada $\alpha=0,01$. Koefisien regresi ini menunjukkan semakin bertambah biaya perjalanan responden ke kawasan penelitian, maka kekerapan kunjungan ke kawasan tersebut semakin berkurang. Sekiranya pengaruh faktor lain dianggap konstan, setiap pertambahan biaya perjalanan Rp100.000 kunjungan akan turun sebanyak $4,3 \%$ atau 0.043 kali kunjungan.

Variabel pendapatan $(P d p t)$ mempunyai hubungan yang positif untuk model yang diestimasi dan signifiken pada $\alpha=$ 0,05 . Koefisien regresi menunjukkan peningkatan setiap Rp1juta pendapatan keluarga, akan meningkatkan kesediaan melawat 0,041\% atau 4.1 kali kunjungan sekiranya faktor lain tidak berubah.

Hasil penelitian juga menunjukkan variabel umur (Um) berhubungan positif dengan kekerapan kunjungan dan signifiken pada $\alpha=0,10$. hasil estimasi menjelaskan bahwa peningkatan umur 1 tahun untuk responden akan meningkatkan kunjungan responden sebanyak $0.003 \%$ atau 0.3 kali kunjungan.

Variabel pendidikan (pendik) memiliki hubungan negatif dengan kunjungan responden ke kawasan penelitian dan signifiken pada $\alpha=0,01$. Semakin meningkatnya tingkat pendidikan 
responden semakin berkurang kesediaan berkunjung ke kawasan penelitian. Ini artinya semakin tinggi pendapatan responden mereka memperhitungkan layanan apa yang didapat atas pengorbanannya.

\section{Langkab II}

\section{ii. Estimasi Surplus Consumen (CS)}

Setelah fungsi permintaan kunjungan dapat dibentuk, kemudian dilanjutkan dengan menghitung surplus konsumen manfaat wisata budaya adat Orang Rimbo dan alam semesta. Nilai surplus konsumen atau manfaat bersih wisata budaya adat Orang Rimbo dan alam semesta setiap kunjungan per responden dihitung menggunakan rumus (1). Mengikut Hanley (1993), spesifikasi fungsi permintaan kunjungan budaya adat Orang Rimbo dan alam semesta adalah semi-log, oleh karena itu surplus konsumen untuk satu kunjungan dapat diestimasi berdasarkan rumus:

$\mathrm{CS}=\left(\frac{\bar{V}}{-\beta}\right) / \bar{V}=\frac{1}{-\beta}$

di mana, $\beta$ yaitu koefisien regresi biaya perjalanan $(K P)$.

Kurve permintaan wisata budaya adat:

$\mathrm{L}_{\mathrm{n}} \mathrm{V}=1,29-0,000035 \mathrm{~K}_{\mathrm{p}}+0,041 \mathrm{P}_{\mathrm{dt}}-0,003 \mathrm{U}_{\mathrm{m}}-0,0095 \mathrm{P}_{\text {endik }}$

Surplus Consumen $(\mathrm{CS})=1 /-(-0,000035)=\mathrm{Rp} 28.571,43$ per responden per kunjungan. Nilai manfaat bersih berdasarkan estimasi surplus konsumen model semi-log sebanyak Rp28.571,43 (US\$2,45) per pengunjung per kunjungan asumsi USD1=Rp13.300,. Nilai ini merupakan nilai budaya adat Orang Rimba dari perspektif masyarakat pengguna.

Surplus konsumen berwisata Budaya Adat Orang Rimbo relatif tinggi jika dibandingkan dengan penelitian yang telah dilakukan Anggi dan Jamal (2009) di kawasan rekreasi Pantai Legenda Parangtritis Yogjakarta yang bernilai US $\$ 1.5$ per pengunjung per kunjungan. Namun nilai wisata Budaya Adat Orang Rimbo mendekati nilai surplus konsumen wisata Budaya Keraton Yogjakarta sebanyak 
US\$2.7 per pengunjung per kunjungan dan dan juga lebih rendah jika dibanding nilai wisata Peninggalan Sejarah Borobudur bernilai US\$14 per pengunjung per kunjungan.

Nilai wisata budaya adat Orang Rimbo juga lebih rendah jika dibanding dengan nilai wisata penelitian yang telah dilakukan Adis Isangkura (1998) di Perkampungan Tradisional Suku Bukit di Taman Nasional Thailand bernilai US $\$ 5.3$ pengunjung per kunjungan. Nilai wisata Budaya Adat Orang Rimbo juga lebih rendah jika dibanding dengan nilai wisata di Desa Tradisional masyarakat setempat di Taman Laut Tioman Malaysia US\$6 pengunjung per kunjungan (Jamal et al 2003). Jasa pariwisata budaya termasuk barang unik karena dari segi penawarannya menghadapi masalah kelangkaan (scarcity) dan tidak mudah mendapatkannya.

\section{Posisi dan Implementasi Hasil Penelitian}

Hasil penelitian surplus konsumen (consumer surplus/CS) adalah sebesar Rp28.571,43 setara US\$2,45. Hal ini menarik karena consumer surplus wisata budaya adat Orang Rimbo dan alam semesta relatif tinggi, sedangkan admission fee sewaktu penelitian berlangsung adalah free (nol rupiah). Ini berarti manfaat (benefit) yang diperoleh oleh setiap pengunjung relatif besar. Apabila admission fee diberlakukan 50\% saja dari consumer surplus, pengunjung masih memperoleh manfaat (benefit) sebesar Rp14.285,71 setara US $\$ 1,07$. Berarti kawasan pariwisata budaya adat Orang Rimbo dan alam semesta mampu memberikan kepuasan serta manfaat ekonomi yang relatif tinggi kepada pengunjung.

Pertimbangan pemberlakuan entrance fee di kawasan wisata haruslah dilakukan dengan memperhitungkan pengaruh terhadap pengunjung baik domestik maupun manca negara. Penetapan entrance fee yang terlalu tinggi menyebabkan berkurangnya jumlah wisatawan dan menurunnya kepuasan pengunjung, sehingga penetapan entrance fee perlu memperhitungkan kemampuan konsumen agar tidak terjadi masalah diskriminasi konsumen.

Hasil penelitian mendapatkan informasi bahwa sebanyak $32,8 \%$ pengunjung menyatakan puas atau mendapat kepuasan atas 
jasa wisata budaya adat Orang Rimbo dan alam semesta. Penyebab rendahnya pengunjung mendapat kepuasan karena kesulitan sarana trasnfortasi umum ke kawasan dan tidak adanya fasilitas seperti; penginapan, rumah makan, toilet, tempat perbelanjaan.

Pembangunan dan perbaikan tempat pariwisata yang memiliki atribut budaya adat dan alam semesta diperlukan untuk dapat menarik dan terus diminati menjadi tujuan wisata yang dikunjungi. Pemerintah Propinsi Jambi, Konservasi sumber Daya Alam (KSDA), dan pihak-pihak yang terkait dengan pengurusan Taman Nasional Bukit Duabelas perlu peduli keadaan dan layanan tempat pariwisata budaya adat Orang Rimbo dan alam semesta. Atribut budaya adat Orang Rimbo dan alam semesta amat penting untuk masyarakat sekarang dan mendatang. Oleh karena itu, atribut tersebut perlu dikonservasi agar keberlanjutan pembangun sesuai dengan budaya masyarakat Orang Rimbo, sehingga sumber daya ini tidak punah dan dapat memberikan manfaat masyarakat.

Dapatan consumersurpluspenelitian ini lebih tinggi dibanding dengan penelitian Anggi dan Jamal (2009) dipantai Parangtritis Yogyakarta. Kawasan wisata pantai parangtritis dan Taman Nasional Bukit Duabelas memiliki kedekatan persamaan yaitu kurangnya fasilitas yang tersedia. Tetapi atribut budaya adat Orang Rimbo ternyata lebih unggul dibanding dengan kemudahan transportasi di Parangtritis. Jika dibanding dengan hasil temuan Anggi dan Jamal (2009) di objek wisata Kraton Ngayogjakarta Hadiningrat consumer surplus-nya relatif mendekati CS Taman Nasional Bukit Duabelas. Ini memberikan pengertian bahwa kedua objek memiliki atribut yang mirip yaitu budaya adat.

Consumer surplus Taman Nasioanl Bukit Duabelas relatif lebih rendah jika dibanding dengan consumer surplus kawasan rekreasi Kampung Tradisional Suku Bukit di Taman Nasional Thailand hasil penelitian Adis Insangkura (1998), juga dengan kawasan wisata Desa tradisional di Taman Laut Tioman Malaysia dan dengan kawasan wisata peninggalan sejarah dunia Candi Borobudur di Indonesia. Ini dikarenakan Kampung Tradisional Suku Bukit, Desa Tradisional Taman Laut Tioman dan Candi Borobudur telah ditata dan diserasikan dengan adat budaya asli masyarakat kawasan tersebut. 
Kaitannya dengan isu konservasi dan isu pembangungan nilai ekonomi kawasan pariwisata budaya adat Orang Rimbo dan wisata alam semesta memiliki arti yang berbeda. Isu konservasi nilai ekonomi pariwisata budaya adat Orang Rimbo dan alam semesta dipandang sebagai manfaat (benefit) dari sumberdaya alam dan budaya. Lain pula pandangan dari segi isu pembangunan, bahwa nilai ekonomi budaya adat Orang Rimbo dan alam semesta menjadi pengorbanan biaya jika kawasan Taman Nasional Bukit Duabelas dikonversi untuk pembangunan yang merubah fungsi untuk pemanfaatan lain, misal untuk perkebunan sawit.

Walaupun temuan nilai ekonomi pariwisata budaya adat Orang Rimbo relatif rendah, tetapi berpotensi menjadi tujuan pariwisata budaya adat yang unik dan menarik untuk wisatawan domestik dan manca negara. Oleh karena itu, para pengambil kebijakan pembangunan yang mengkonversi kawasan untuk kegunaan lain hendaklah mempertimbangkan nilai tersebut dalam keputusannya.

\section{Kesimpulan}

Penelitan ini berhubungan pendekatan pendidikan orang Rimbo dan masyarakat sekitar serta nilai ekonomi pariwisata budaya khususnya budaya adat masih sangat langka. Penerapan model biaya perjalanan atau TCM di Indonesia merupakan model baru di bidang valuasi ekonomi. Terdapat dua implikasi dasar yang penting dari penemuan penelitian ini. Pertama, masalah baik operasi TNBD dilanjutkan dan kedua, potensi peningkatan pendanaan untuk membiayai operasi dan perbaikan kualitas pelayanan.

Dengan asumsi USD1=Rp13.300 model MBP/TCM perspektif lower bound estimation diperoleh nilai rekreasi budaya adat Orang Rimba dalam penelitian ini adalah sebanyak US\$2,45 per pengunjung per kunjungan. Nilai ini membentuk kehilangan manfaat pariwisata budaya adat sekiranya Taman Nasional Bukit Duabelas dikonversi kegunaan lain. Nilai ini berfungsi pada jumlah kunjungan serta kepuasan yang diperoleh setiap pengunjung, peningkatan 
jumlah pengunjung serta peningkatan dalam kepuasan akan meningkatkan nilai manfaat ini. Sebaliknya nilai manfaat ini dapat kurang sekiranya jumlah kunjungan dan kepuasan yang diperoleh pengunjung turun. Dan nilai yang diestimasi dalam penelitian ini hanya mewakili nilai jasa wisata budaya adat Orang Rimbo, tidak memperhitungkan nilai lain selain nilai pariwisata yang dibentuk dalam fungsi ekologi.

Rendahnya nilai manfaat dibanding dengan biaya operasional (manajement) sebuah Taman Nasional, Taman Nasional Bukit Duabelas tidak layak beroperasi. Selanjutnya persoalan yang perlu diperhatikan adalah apakah terdapat prospek meningkatkan pelayanan untuk meminta bayaran masuk kawasan yang wajar kepada pengunjung. Penelitian ini memperoleh nilai surplus konsumen adalah sebanyak Rp28,571,43.18 setara US $\$ 2,45$ per pengunjung per kunjungan asumsi USD1=Rp13.300. Nilai surplus konsumen yang rendah ini menunjukkan tidak terdapat sekop yang banyak untuk bayaran masuk tanpa mempengaruhi kesejahteraan pengunjung dan jumlah kunjungan secara signifikan.

Sumber pendanaan untuk taman-taman wisata publik biasanya dari dua yaitu dari pemerintah dan bayaran masuk kawasan. Sekiranya tidak terdapat sekop yang luas pihak manajement untuk menaikkan bayaran masuk ke kawasan agar menambah sumber pendanaan. Oleh karena itu sumber pendanaan lain yang imperatif untuk meneruskan operasi serta melakukan perbaikan diperlukan agar dapat memberikan kepuasan dan dayatarik tambahan kepada pengunjung. Penambahan pendanaan dapat dilakukan melalui sumber anggaran pemerintah atau sumber pinjaman.

Disarankan manajement Taman Nasional Bukit Duabelas di dikelola oleh swasta atau badan usaha milik negara (BUMN/ BUMD). Bagaimanapun, penelitian secara menyeluruh tentang kelayakan saran ini adalah diperlukan. Perubahan manajement pengelolaan berpotensi membawa perubahan dalam pengaruh pembiayaan, sumber dana maupun efisiensi pengelolaan. Adanya pesaing kawasan pariwisata lain, inovasi dan pendekatan strategi 
baru diperlukan untuk meningkatkan dayatarik wisatawan disamping tetap memperhatikan keberlanjutan lingkungan yang ada sekarang.

Kawasan pariwisata Taman Nasional Bukit Duabelas wajar dilindungi untuk melindungi budaya adat Orang Rimbo. Walaupun penelitian mendapati rendahnya keterlibatan orang rimbo dan masyarakat sekitar serta nilai pariwisata budaya adat yang rendah. Kawasan wisata budaya adat Orang Rimbo adalah salah satu dari budaya suku bangsa Indonesia yang memiliki keunikan. Dengan keunikan budaya adat Taman Nasional Bukit Duabelas berpotensi menjadi tujuan wisatawan eko-budaya dalam negara serta internasional.

\section{Daftar Pustaka}

Adis Isangkura. 1998. Environmental Valuation: An Entrance Free System for National Parks in Thailand. EEPSEA Research Report Series, RR 1998-091.

Balai Konservasi Sumber Daya Alam (BKSDA) Jambi. 2004. Taman Nasional Bukit Duabelas. Rencana Pengelolaan 2005 -2029. Jambi, Indonesia.

BPS.2005. Beberapa Indikator Penting Sosial Ekonomi Indonesia.

BPS.2006. Beberapa Indikator Penting Sosial Ekonomi Indonesia.

BPS.2007. Beberapa Indikator Penting Sosial Ekonomi Indonesia.

BPS.2008. Beberapa Indikator Penting Sosial Ekonomi Indonesia.

BPS.2009. Beberapa Indikator Penting Sosial Ekonomi Indonesia.

Cesario, F. J. 1976. Value of time in recreation benefit studies. Journal Land Economics 52 (1): 32-41.

Carroll, R \& Tansey, R .2000. 'Intellectual capital in the new internet economy: its meaning, measurement and management 
for enhancing quality.', Journal of Intellectual Capital. (1) 4. pp. 296-311.

Dewi Nurfitriyana, 2010. Inovasi Pemanfaatan Aset Pariwisata Budaya Kota Yogjakarta. Tugas akir. Tugas akir. Fakultas Teknik Universitas Diponegoro.

https://core.ac.uk/downlood/pdf/18606027.pdf. Diakses 19-1-2017.

Fauzi A . 2004. Ekonomi Sumberdaya Alam dan Lingkungan. Jakarta. PT Gramedia.

Fletcher, J.,Adamowicz,W.\&Graham-Tomasi,T. 1990. The Travel Cost Model of Recreation Demand: Theoritical and Empirical Issues. Leisure Science. 12:119-147.

Freeman, A.M. 1993. The Measurement of Environmental and Resource Values, Theory and Methods. Washington: Resources for the Future.

Gum, R. L. \& Martin, W. E. 1975. Problems and solutions in estimating the demand for and value of rural outdoor recreation. American Journal of Agricultural Economics 57: 558-566.

Garrod, G., \& Willis, K. G. 2001. Economic valuation of the environment: methods and case studies. Cheltenham: Edward Elgar.

Gujarati, D. N. 2003. Basic econometric. New York: McGraw-Hill.

Gubernur Jambi. 2005. Keputusan penetapan tarif minimum maksimum penumpang antar kota kelas ekonomi dengan bus umum.

Hanley, Nick \& Spash, Clive. L. 1993. Cost-Benefit Analysis and the Environment. Edward Elgar Publishing Limited. 
Hanley, N. D. 1989. Valuing rural recreation benefits: an empirical comparison of two approach. Journal of Agricultural Economics . 40: 361-374.

Hit, Michael A., R. Duane Ireland dan Robert Hoskinson. 2001. Manajemen Strategis: Daya Saing dan Globalisasi. Jakarta: Salemba Empat.

Hood Salleh, Sharina, A Halim \& Sanizah. 2004. Man A Pact With The Change, Identity And New Environment For Orang Ash of Malaysia. An International Seminar on Multidisiplinary Discource, Jointly organized by Fo Guang University. Taiwan and The National University of Malaysia. Bangi,on 16-17 $7^{\text {th }}$ February 2004, in UKM, Bangi, Selangor, Malaysia.

Jamal Othman \& Redzuan Othman, 1998.Economic benefits of wetlands biodiversity: Case of fireflies recreation. Tropical Biodiversity 5 (1), 65-74

Jamal Othman, 2000. Economic benefits of wetlands-based recreation: Case of Kuala Selangor fireflies and nature park. Malaysian Journal of Environmenral Management. (1). 41-54.

Jamal. 2001. Estimating non-use values of environmental resources using. contingent valuation: case of Matang Mangroves. Dlm. Jamaluddin Jahi (pnyt.) Environmental management 2000, hlm. 214-222. Universiti Kebangsaan Malaysia: Center for Graduate Studies.

Jamal Othman.,Basri Abadul Talib.,Redzuan Othman., 2004. Nilai Ekonomi Khidmat Rekreasi Taman Pertanian Malaysia, Shah Alam. IJMS 11 (1), 165-179.

Kayam, Umar. 1996. Kebudayaan dan Budaya Perusahaan. Manajemen Usahawan Indonesia 07/XXV. 
KKI WARSI, 2004. Laporan pendataan Suku Anak Dalam (Orang Rimbo), Jambi Indnesia.

Kumari Kanta. 1994. Sustainable Forest Managemant in Peninsular Malaysia: Towards a Total Economic Valuation Approach. East Anglia University. DX1802.

Larson, D.M. 1992. Further result on willingness to pay for nonmarket goods. Journal of Environmental Economics and Manajement. (23):1001-122.

Landiyanto, Erlangga Agustino and Wardaya, Wirya. 2009. Framework of Regional Development in Agenda 21: Sustainability and Environmental Vision. Airlangga University dalam http://mpra.ub.uni-muenchen.de/2381/ diakses 10 Oktober 2009 jam 10.20 WIB.

Priyanto dan Dyah Safitri, 2016. Pengembangan potensi desa wisata berbasis budaya tinjauan terhadap desa wisata di Jawa tengah. Jurnal Vokasi Indonesia UI Vol 4 Nomer 1. Pp 76-84. jvi.ui.ac.id/index.php/jvi/article/download/53/51 diakses 19-1-2017.

Ravi Gopal. 2005. Indigenous Environmental Knowledge in Formal Education. Jurnal Penyelidikan. MPBL, 6.

Soo-Hoon Lee., Poh Kam Wong and Chee Leong Chong. 2005. Human and Sosial Capital Explanations for R\&D Outcomes IEEE Transactions on Engineering Management.52 (1) p 5968.

Suib, A.,1991. Effects of time cost on recreational benefit estimation. Malaysian Journal of Environmental Economics and Management. (23):101-122.

Willis,K., Garrod,G \& Chee T. 1996. Valuation and analysis of consumer demand for forest recreation areas in Peninsula Malaysia. In S.Lee, D. May, I.Gauld and J. Bishop (Eds). 
Conservation, Mangement and Development of forest Resource. Proceedings of the Malaysia-UK Programme Workshop. Forest Research Institute Malaysia. 